\title{
Recurrence of COVID-19 Documented with RT-PCR
}

\author{
Rohat $A k^{1}$, Erdal Yilmaz ${ }^{1}$, Avni Uygar Seyhan ${ }^{1}$ and Fatih Doganay ${ }^{2}$ \\ ${ }^{1}$ Department of Emergency Medicine, Kartal Dr. Lutfi Kirdar City Hospital, Turkey \\ ${ }^{2}$ Department of Emergency Medicine, Edremit Public Hospital, Turkey
}

\begin{abstract}
We present a case of coronavirus disease 2019 (COVID-19) re-infection where the time interval between two COViD-positive episodes is the longest in the literature. A 40-year male patient was admitted to the Emergency Department with complaints of sore throat, cough and diarrhea; and was re-diagnosed as COVID-19 positive after a virus-free period. He did not have a chronic disease in his anamnesis and used no medication. After COVID-19 infection and a long recovery period, he became COVID-19 positive again. In this case, the time to second COVID-19 infection was 94 days from the first positive PCR test and 86 days from the complete resolution of symptoms. This is one of the longest COVID-19-free period between two episodes of infection in the literature.
\end{abstract}

Key Words: COVID-19, Recurrence, Re-infection, Recovery.

How to cite this article: Ak R, Yilmaz E, Seyhan AU, Doganay F. Recurrence of COVID-19 Documented with RT-PCR. J Coll Physicians Surg Pak 2021; 31(JCPSPCR):CR26-CR28.

\section{INTRODUCTION}

Coronavirus disease 2019 (COVID-19) is a viral illness caused by infection with the Severe acute respiratory syndrome coronavirus 2 (SARS-CoV-2), a coronavirus strain. Before spreading globally, the initial patients were detected in Wuhan, China, in December 2019, and now over 25 million confirmed cases have been identified. ${ }^{1}$ Covid- 19 was officially declared pandemic by the World Health Organization (WHO) on March 11, 2020. ${ }^{2}$ In April 2020, the first cases of repeat positive COVID-19 PCR tests after recovery from COVID-19 infection were reported from South Korea. Here, we report a case of a patient with PCR-confirmed COVID-19, who experienced re-infection after negative PCR testing. To the best of authors' knowledge, this report is novel in the literature as it describes a recurrence of COVID-19 in an apparently cured COVID-19 patient in Turkey. In addition, it is the case of COVID-19 re-infection, where the time interval between two COVID-19-positive episodes in a patient is one of the longestin the literature.

\section{CASE REPORT}

A 40-year male patient presented to the Emergency Department (ED) with fever and cough on April 9, 2020. Vital signs were normal except for $37.3^{\circ} \mathrm{C}$ temperature at admission.

Correspondence to: Dr. Rohat Ak, Department of Emergency Medicine, Kartal Dr. Lütfi Kırdar City Hospital, Turkey

E-mail: rohatakmd@gmail.com

Received: September 14, 2020; Revised: November 27, 2020; Accepted: December 04, 2020

DOI: https://doi.org/10.29271/jcpsp.2021.JCPSPCR.CR26
There was no chronic disease in his anamnesis and he did not use any medication. There was no significant pathology on chest computed tomography (CT) (Figure 1). The reverse transcription-polymerase chain reaction (RT-PCR) performed on a sample collected from a nasopharyngeal swab, collected on April 9, was positive for SARS-CoV-2. He was started on the standard hydroxychloroquine regimen ( $400 \mathrm{mg}$ twice on the 1st day, then $400 \mathrm{mg}$ on the 2nd-5th days, daily) and was discharged with self-isolation recommendations. In the subsequent followup of the patient, two seperate swabs collected on April 16 and 23 showed no evidence of SARS-CoV-2 infection and the patient's complaints were completely resolved.

On 12 July, 2020, the patient presented to an another hospital with sore throat, cough and diarrhea. The nasopharyngeal swab taken from the other hospital on 12 July was found positive for SARS-CoV-2. The patient was transferred to this hospital, which is a pandemic hospital, on July 13, when the test result was released. The patient's complaints of sore throat, cough and diarrhea were continuing. Vital signs measured at the time of admission showed temperature as $37.9^{\circ} \mathrm{C}$, pulse $77 / \mathrm{min}$, blood pressure $100 / 80 \mathrm{mmHg}$, oxygen saturation $98 \%$ on room air. Bilateral ground glass shadows were observed on chest CT (Figure 2). Laboratory tests including liver function tests, renal function tests, myocardial enzymes and electrolytes were normal except white blood cells, which were $3.7 \times 10^{3} / \mu \mathrm{L}$ (Normal range: 4.8-10.8 $\times 10^{3} / \mu \mathrm{L}$ ); and platelet count, which was $100 \times 10^{3} / \mu \mathrm{L}$ (Normal range: $130-400 \times 10^{3} / \mu \mathrm{L}$ ).

The patient was admitted to hospital and was treated with hydroxychloroquine ( $400 \mathrm{mg}$ b.i.d on the first day, and then 200 $\mathrm{mg}$ b.i.d for 6 days), enoxaparin, $4000 \mathrm{IU}$ bd., and moxifloxacin (400 mg for 7 days). On the 8th day of treatment, the patient's complaints completely resolved, and he was discharged with 
self-isolation recommendations. In the patient's subsequent follow-ups, two other swabs obtained on July 28 and 31 were negative for SARS-CoV-2 (Figure 3).

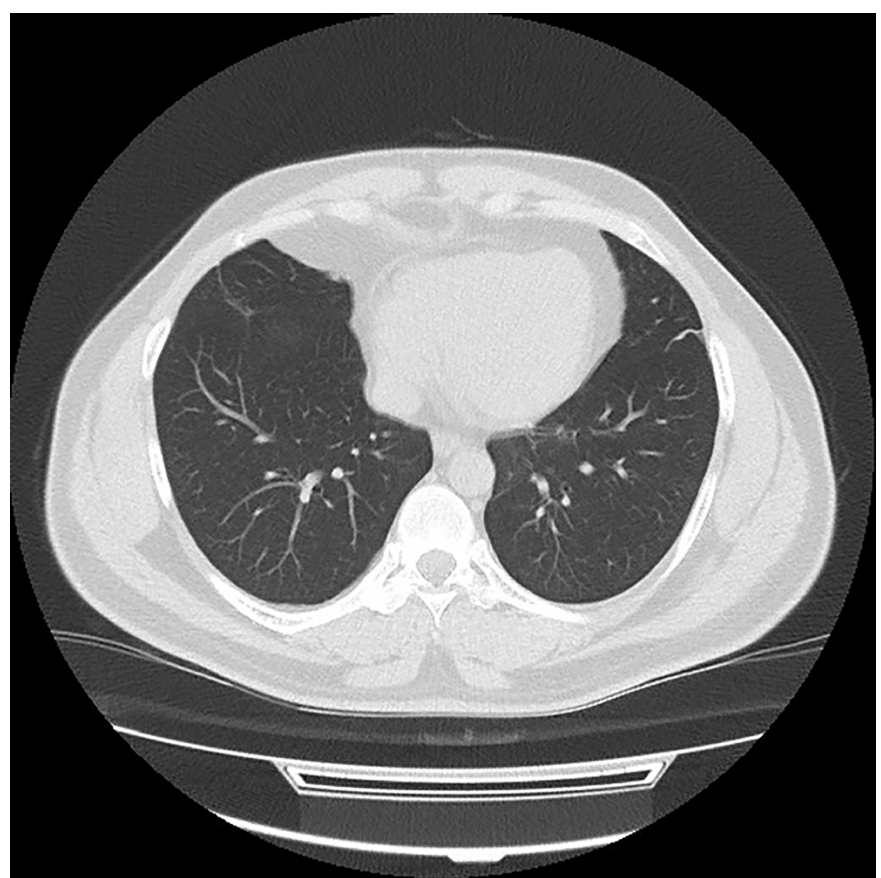

Figure 1: There is no pathology on the chest CT during the first episode of theinfection.

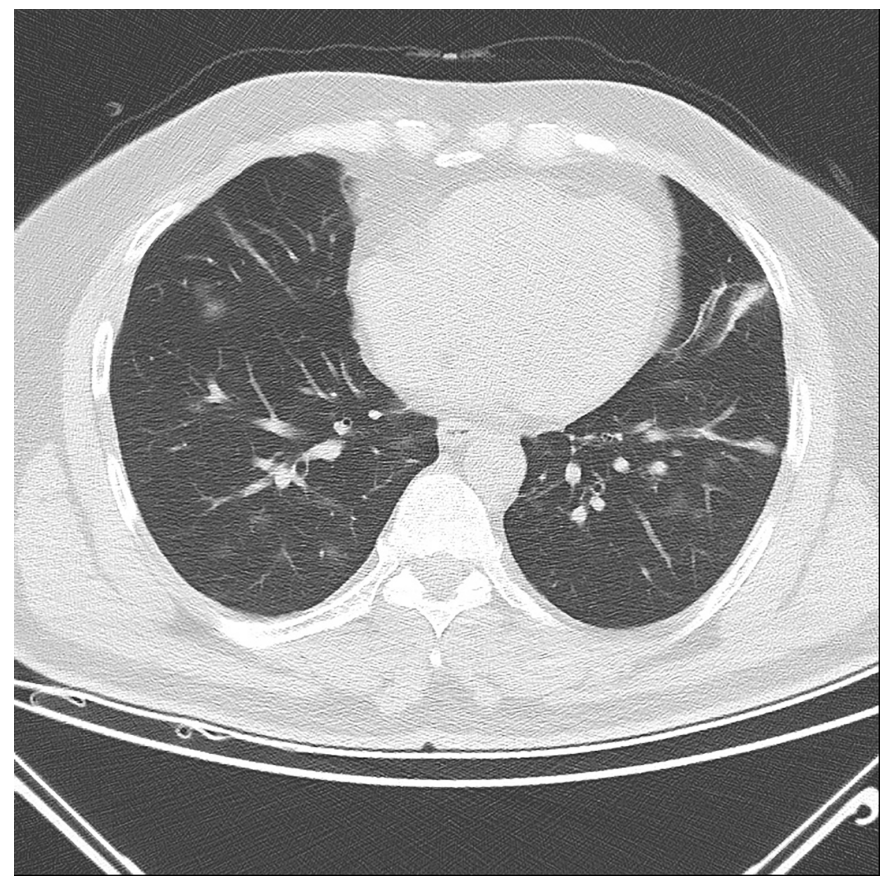

Figure 2: Bilateral ground glass shadows were observed on chest CT at the second episode of the infection.

\section{DISCUSSION}

There is currently no curative treatment for COVID-19. Cases of COVID-19 'relapse' or 'reactivation' have recently been reported in the literature. ${ }^{4-6}$ For COVID-19, which is a global public health problem, it is currently not possible to predict in which patients, relapse or reactivation will occur and when.
Ye et al. reported $9 \%$ recurrence in COVID-19 patients occurring after the patients left the hospital setting. The timing of reactivation for SARS-COV-2 may vary depending on host factors, underlying disease, and immunosuppressive conditions such as steroid use. ${ }^{4}$

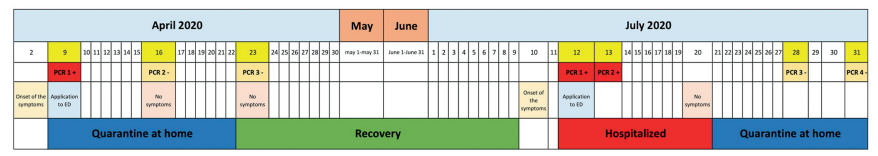

Figure 3: Progress chart of the patient with recurrent COVID-19 infection.

Virological factors causing risk of reactivation include high initial viral load and variations in genotype. The SARS-CoV-2 viral load is also associated with response to treatment, severity of disease, and progression. ${ }^{7}$ In the case we presented, the patient did not have any additional disease, immunosuppression, or any medication.

Immunity to SARS-COV-2 occurs through a combination of cell-mediated and humoral responses, but the degree of protection from re-infection is as yet unknown. ${ }^{8}$ Loconsole et al. reported a COVID-19 patient who showed reactivation despite IgG being positive, as well as multiple cases of recurrence despitelgG positivity. ${ }^{6}$

Immunosuppressive factors including, but not limited to drugs or certain diseases, may cause impaired viral clearance and allow occurence of SARS-CoV-2 reactivation. ${ }^{9}$ Batisse et al. reported that in a case series of 11 patients with COVID-19 reactivation, three patients received corticosteroids and two patients received chemotherapy during the first episode. ${ }^{10}$ In the study of Ye etal., three patients, who experienced COVID-19 reactivation, received corticosteroids during the first episode. ${ }^{4}$ In the case we presented, the patient was not taking any immunosuppressive or corticosteroid-containing medications and had no known immunosuppressive disease.

In the study of Ye et al., the time interval between episodes of SARS-CoV-2 positivity ranged from 4 to 17 days. ${ }^{4}$ Recently, To et al. reported a case of COVID-19 re-infection, in which the second episode of infection occurred 142 days after the first episode. ${ }^{11}$ In this case, the time to second episode of COVID-19 infection was 94 days after the first positive PCR test and 86 days after the resolution of symptoms in the first episode (Figure 3 ). This is one of the longest COVID-19-free period between two episodes of infection in the literature.

\section{PATIENT'S CONSENT:}

Written informed consent was obtained from the patient to publish the data concerning this case.

\section{CONFLICT OF INTEREST:}

Authors declared no conflict of interest.

\section{AUTHORS' CONTRIBUTION:}

RA, AUS, EY, FD: Have collected data, searched the literature, written the case report and reviewed the final version of the manuscript. 
All authors had access to the manuscript at every stage of the preparation. They approved the upload of the manuscript all together.

\section{REFERENCES}

1. Zhu N, Zhang D, Wang W, Li X, Yang B, Song J, et al. A novel coronavirus from patients with pneumonia in China. N Eng J Med 2020; 382(8):727-33. doi: 10.1056/NEJM oa2001017.

2. World Health Organization. (2020). WHO DirectorGeneral's opening remarks at the media briefing on COVID-19-11 March 2020.

3. Smith J. April 2020: www.reuters.com/article/ us-healthcoronavirus-southkorea/south-korea-reports-morerecovered- coronavirus-patients-testing-positive- againidUSKCN21V0JQ.

4. Ye G, Pan Z, Pan Y, Deng Q, Chen L, Li J. Clinical characteristics of severe acute respiratory syndrome coronavirus 2 reactivation. J Infect 2020; 80(5):e14e17. doi: 10.1016/j.jinf.2020.03.001.

5. Ravioli S, Ochsner H, Lindner G. Reactivation of COVID-19 pneumonia: A report of two cases. J Infect 2020; 81(2):72-e3. doi: 10.1016/j.jinf.2020.05.008.

6. Loconsole D, Passerini F, Palmieri VO, Centrone F, Sallustio A, Pugliese S. Recurrence of COVID-19 after recovery: A case report from Italy. Infection 2020;
48(6):965-7. doi: 10.1007/s15010-020-01444-1.

7. Zou L, Ruan F, Huang $M$, Liang L, Huang $H$, Hong $Z$, et al. SARS-CoV-2 viral load in upper respiratory specimens of infected patients. N Eng J Med 2020; 382(12):1177-1179. doi: 10.1056/NEJMc2001737.

8. Grifoni A, Weiskopf D, Ramirez SI, Mateus J, Dan JM, Moderbacher $C R$, et al. Targets of $T$ cell responses to SARS-CoV-2 coronavirus in humans with COVID-19 disease and unexposed individuals. Cell 2020; 181(7):1489-1501. doi: 10.1016/j.cell.2020.05.015.

9. Ling $Y, X u S B$, Lin $Y X$, Tian D, Zhu ZQ, Dai FH, et al. Persistence and clearance of viral RNA in 2019 novel coronavirus disease rehabilitation patients. Chinese Med J 2020; 133(9):1039-43. doi: 10.1097/CM9.00000000000 00774.

10. Batisse D, Benech N, Botelho Nevers E, Bouiller K, Collarino $\mathrm{R}$, Conrad $A$, et al. Clinical recurrences of COVID-19 symptoms after recovery: viral relapse, reinfection or inflammatory rebound? J Infec 2020; 81(5): 816-46. doi: 10.1016/j.jinf.2020.06.073.

11. To KKW, Hung IFN, Ip JD, Chu AWH, Chan WM, Tam AR, et al. Coronavirus disease 2019 (COVID-19) re-infection by a phylogenetically distinct severe acute respiratory syndrome coronavirus 2 strain confirmed by whole genome sequencing. Clin Infec Dis 2020; doi.org/10.1093/ cid/ciaa1275. 